\title{
Validated Stability Indicating Liquid Chromatographic Method for Simultaneous Estimation of Dosulepin and Methylcobalamin In Combined Pharmaceutical Dosage Form
}

\author{
L.SHIVAKUMAR REDDY ${ }^{1 *}$, S.L.N.PRASAD REDDY ${ }^{2}$ and G.SRINIVAS REDDY ${ }^{3}$ \\ ${ }_{1,3}$ Research Scholars, Department of Pharmaceutical Sciences, \\ Jawaharlal Nehru Technological University, Hyderabad Andhra Pradesh, India. \\ ${ }^{2}$ Principal, Sanskruthi College of Pharmacy, Ghatkesar, Hyderabad, India. \\ Corresponding author E-mail: shivanarendra@gmail.com \\ http://dx.doi.org/10.13005/ojc/300340
}

(Received: July 07, 2014; Accepted: August 06, 2014)

\begin{abstract}
A novel stability indicating reversed-phase liquid chromatographic method has been developed and validated for simultaneous estimation of Dosulepin hydrochloride and Methylcobalamin in combined pharmaceutical dosage form. An Inertsil-ODS (250mmx4.6mmx5mic) column with mobile phase containing $0.02 \%$ Orthophosphoric acid and Methanol (400:600 v/v) was used. The flow rate was maintained at $1.0 \mathrm{~mL} / \mathrm{min}$, column temperature was $30^{\circ} \mathrm{C}$ and effluents were monitored by using a photodiode array detector at $223 \mathrm{~nm}$. The retention times of Dosulepin and Methylcobalamin were found to be $2.633 \mathrm{~min}$ and $3.794 \mathrm{~min}$, respectively. Correlation co-efficient for Dosulepin and Methylcobalamin were found to be 0.99 and 0.99 , respectively. The proposed method was validated with respect to linearity, accuracy, precision, specificity, and robustness. Recovery of Dosulepin and Methylcobalamin in formulations was found to be in a range of $97-103 \%$ and $97-103 \%$ respectively. Dosulepin hydrochloride and Methylcobalamin were also subjected to the stress conditions of oxidative, acid, base, hydrolytic, thermal and photolytic degradation. The degradation products were well resolved from and peak purity test results confirmed that Dosulepin and Methylcobalamin peaks were homogenous and pure in all stress samples, thus proving stability-indicating power of the method. Due to its simplicity, rapidness and high precision, this method can be applied for regular analysis.
\end{abstract}

Key words: Dosulepin, Methylcobalamin, Liquid chromatography, Method validation, Forced degradation

\section{INTRODUCTION}

Dosulepin (INN), formerly known as dothiepin (BAN), is a tricyclic antidepressant (TCA). It is chemically 3 -(dibenzo[b,e]thiepin-11(6H)ylidene)-N,N-dimethylpropan-1-amine (Figure-I). It is sold under the brand names Prothiaden, Dothep, Thaden and Dopress. Dosulepin blocks the reuptake of serotonin and norepinephrine in the brain, thereby increasing their levels. It is believed that this action is responsible for its mood-elevating effects. 
Methylcobalamin (mecobalamin, MeCbl, or MeB12) is a cobalamin, a form of vitamin B12. It differs from cyanocobalamin in that the cyanide is replaced by a methyl group. Methylcobalamin features an octahedral cobalt (III) centre (Fig. 1). Methylcobalamin is equivalent physiologically to vitamin $\mathrm{B} 12$, and can be used to prevent or treat pathology arising from a lack of vitamin B12 (vitamin B12 deficiency), such as pernicious anemia. Methylcobalamin is also used in the treatment of peripheral neuropathy, diabetic neuropathy, and as a preliminary treatment for amyotrophic lateral sclerosis $^{1-2}$. Chemical structures of Dosulepin and methylcobalamin are presented in Fig. 1.

A literature survey revealed few liquid chromatography (LC) assay methods that have been reported for the determination of Dosulepin hydrochloride in bulk dug and pharmaceutical dosage forms, but there are no reported methods for simultaneous estimation of Dosulepin hydrochloride and Methylcobalamin in combined pharmaceutical dosage forms ${ }^{3-13}$.

The present International Conference on Harmonization (ICH) drug stability guidelines suggest that stress studies should be conducted on the drug product to establish its inherent stability characteristics, and the analytical method should able to separate all degradation impurities formed under stress studies to prove its stability-indicating power. In order to monitor possible changes to a product over time, the applied analytical chromatographic method must be stability-indicating. The best case for testing the suitability of a method is using real-time stability samples containing all relevant degradation products that might occur. But due to product development timelines, process characteristics, excipients, and other environmental factors, a forced degradation study (stress test) can serve as an alternative ${ }^{14-19}$.

The aim of the present work is to focus on the development of an efficient stability indicating liquid chromatographic method for simultaneous estimation of Dosulepin hydrochloride and Methylcobalamin in combined pharmaceutical dosage form such as Tablets in presence of its excipients and degradation products in a short chromatographic run.

The present work concerns the method

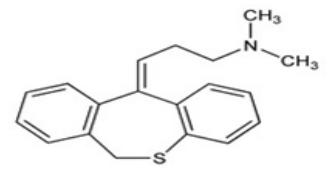

(A)

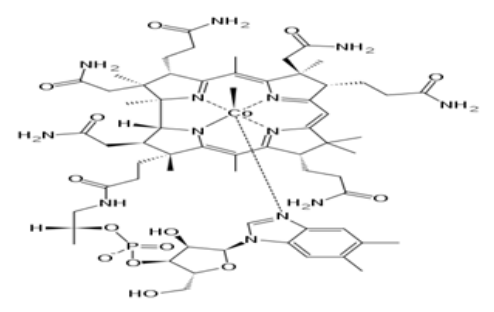

(B)

Fig. 1: Chemical structures of Dosulepin and methylcobalamin

development, method validation and forced degradation studies of Dosulepin hydrochloride and Methylcobalamin in combined pharmaceutical dosage form. The developed Liquid Chromatographic method was validated with respect to specificity, limit of detection (LOD), limit of quantification (LOQ), linearity, precision, accuracy and robustness. Forced degradation studies were performed on the placebo and drug products to show the stability-indicating nature of the method. These studies were performed in accordance with established $\mathrm{ICH}$ guidelines.

\section{EXPERIMENTAL}

\section{Instrumentation}

Samples were analyzed on Waters alliance 2695 HPLC system (Waters Corporation, Milford, MA) equipped with a with binary HPLC pump, Waters 2998 PDA detector and Waters Empower2 software. The separation was achieved on Inertsil-ODS (250 $\mathrm{mm} \times 4.6 \mathrm{~mm} \times 5 \mu \mathrm{m}$ ) column.

\section{Chemicals and Reagents}

Dosulepin hydrochloride and Methylcobalmin standards were supplied by Dr. Reddy's Laboratories Ltd., Hyderabad. Methanol of HPLC grade was purchased from E. Merck (India) Ltd., Mumbai. Orthophosphoric acid of AR grade was obtained from S.D. Fine Chemicals Ltd., Mumbai and milli $Q$ water. Dosulepin hydrochloride and Methylcobalmin film coated tablets (Abott Laboratories: ProthiadenM) were procured from market. 


\section{HPLC Conditions}

The mobile phase consisting of $0.2 \% \mathrm{v} / \mathrm{v}$ ortho phosphoric acid and methanol (HPLC grade) were filtered through $0.45 \mu \mathrm{m}$ membrane filter before use, degassed and were pumped from the solvent reservoir in the ratio of $400: 600 \mathrm{v} / \mathrm{v}$ into the column at a flow rate of $1.0 \mathrm{ml} / \mathrm{min}$. The column temperature was maintained at $30^{\circ} \mathrm{C}$. The detection was monitored at $223 \mathrm{~nm}$ and the run time was 8 minutes. The volume of injection loop was $10 \mu$ prior to injection of the drug solution.

\section{Preparation of standard solution}

Accurately weighed quantity, 150.0 $\mathrm{mg}$ of Dosulepin hydrochloride and $3.0 \mathrm{mg}$ of Methylcobalamin was transferred into $50 \mathrm{ml}$ of volumetric flask and diluted to the volume with mobile phase. From this stock, $5 \mathrm{ml}$ of solution was taken into a $10 \mathrm{ml}$ volumetric flask and diluted to the volume with mobile phase (Concentration of Dosulepin : $0.15 \mathrm{mg}$ / $\mathrm{ml}$, Concentartion of Methylcobamin : $0.03 \mathrm{mg} / \mathrm{ml}$ ).

\section{Preparation of sample (drugs from marketed formulations) solution}

Twenty tablets were weighed and the average weight was calculated and crushed in to the fine powder, Tablet powder (Equivalent to two tablets) was transferred into $50 \mathrm{ml}$ of volumetric flask and diluted to the volume with mobile phase. From this stock solution $5 \mathrm{ml}$ was transferred into a $10 \mathrm{ml}$ volumetric flask and diluted to the volume with mobile phase.(Concentration of Dosulepin : $0.15 \mathrm{mg} /$ $\mathrm{ml}$, Concentartion of Methylcobamin : $0.03 \mathrm{mg} / \mathrm{ml}$ ).

\section{Forced degradation studies}

Forced degradation studies were performed at a $612 \mathrm{mg} / \mathrm{mL}$ concentration of Dosulepin hydrochloride and Methylcobalamin in tablets to provide an indication of the stability-indicating property and specificity of the proposed method. A peak purity test was conducted for Dosulepin hydrochloride and Methylcobalamin peaks by using a PDA detector on stress samples. All solutions used in forced degradation studies were prepared by dissolving the drug product in a small volume of stressing agents. After degradation, these solutions were diluted with mobile phase to yield a stated concentration approximately. Conditions employed for performing the stress studies are described below.

\section{Acid degradation}

Tablet powder equivalent to $612.20 \mathrm{mg}$ was accurately weighed and dissolved in $5 \mathrm{ml}$ of mobile phase, $5 \mathrm{ml} 5 \mathrm{~N} \mathrm{HCl}$ was added and the mixture was kept at $70^{\circ} \mathrm{C}$ for $5 \mathrm{~min}$. The solution was brought to ambient temperature, neutralized by the addition of $5 \mathrm{ml} 5 \mathrm{~N} \mathrm{NaOH}$ and diluted to $25 \mathrm{ml}$ with mobile phase.

To prepare the blank, $5 \mathrm{~mL}$ of $5 \mathrm{~N} \mathrm{HCl}$ and $5 \mathrm{~mL}$ of $5 \mathrm{~N} \mathrm{NaOH}$ were diluted to $25 \mathrm{~mL}$ with mobile phase.

\section{Base degradation}

Tablet powder equivalent to $612.20 \mathrm{mg}$ was accurately weighed and dissolved in $5 \mathrm{ml}$ of mobile phase, $5 \mathrm{ml} 5 \mathrm{~N} \mathrm{NaOH}$ was added and the mixture was kept at $70^{\circ} \mathrm{C}$ for $5 \mathrm{~min}$. The solution was brought to ambient temperature, neutralized by the addition of $5 \mathrm{ml} 5 \mathrm{~N} \mathrm{HCl}$ and diluted to $25 \mathrm{~mL}$ with mobile phase.

To prepare the blank, $5 \mathrm{~mL}$ of $5 \mathrm{~N} \mathrm{NaOH}$ and $5 \mathrm{~mL}$ of $5 \mathrm{~N} \mathrm{HCl}$ were diluted to $25 \mathrm{~mL}$ with mobile phase.

\section{Oxidation degradation}

Tablet powder equivalent to $612.20 \mathrm{mg}$ was accurately weighed and dissolved in $5 \mathrm{~mL}$ of mobile phase, $5 \mathrm{~mL}$ of $3 \%$ hydrogen peroxide was added and the mixture was kept at $70^{\circ} \mathrm{C}$ for $10 \mathrm{~min}$. The solution was brought to ambient temperature and diluted to $25 \mathrm{~mL}$ with mobile phase.

To prepare the blank, $5 \mathrm{ml}$ of $3 \%$ hydrogen peroxide was diluted to $25 \mathrm{~mL}$ with mobile phase.

\section{Thermal degradation}

Tablet powder equivalent to $612.20 \mathrm{mg}$ was stored at $105^{\circ} \mathrm{C}$ for $9 \mathrm{~h}$, dissolved and diluted to 25 $\mathrm{mL}$ with mobile phase.

\section{Photolytic degradation}

The susceptibility of the drug product to the light was studied; Tablet powder for photo stability testing was placed in a photo stability chamber and exposed to a white florescent lamp with an overall illumination of 1.2 million lux hours and near UV radiation with an overall illumination of $200 \mathrm{watt} / \mathrm{m} 2 / \mathrm{h}$ at $25^{\circ} \mathrm{C}$. Following removal from the photo stability 
chamber, the sample was prepared for analysis as previously described.

\section{RESULTS AND DISCUSSION}

\section{Method Development}

The analytical procedure for the estimation of Dosulepin hydrochloride and Methylcobalamin in marketed formulation was optimized with a view to develop a precise and accurate assay method. Agilent Eclipse XDB (4.6*150mm³.5mic), Agilent Zorbax C8 (4.6*150mm*5mic) and Inertsil-ODS $\left(4.6^{\star} 250 \mathrm{~mm}{ }^{\star} 5 \mathrm{mic}\right)$ were used to provide an efficient separation but appropriate chromatographic separation was achieved on Inertstil-ODS $\left(4.6{ }^{\star} 250 \mathrm{~mm}{ }^{\star} 5 \mathrm{mic}\right)$. Various mobile phase systems were prepared and used to provide an appropriate chromatographic separation, but the proposed mobile phase containing $0.2 \% \mathrm{v} / \mathrm{v}$ Orthophoshoric acid: Methanol in the ratio of 400:600 (v/v) gave a better resolution. Using UV-visible PDA detector at $223 \mathrm{~nm}$ carried out the detection. Amongst the several flow rates tested, the flow rate of $1 \mathrm{ml} / \mathrm{min}$ was the best suited for both the drugs with respect to location and resolution of peaks. The retention time of Dosulepin and methylcobalmin was found to be $2.633 \mathrm{~min}$ and $3.794 \mathrm{~min}$ respectively. The chromatograms of standard and sample solution of Dosulepin hydrochloride and Methylcobalmin were shown in Fig. 2. The asymmetry factor of Dosulepin hydrochloride and methylcobalmin was 1.158 and 1.149 found to be respectively, which indicates symmetrical nature of the peak. The USP resolution of 7.957 was achieved between Dosulepin hydrochloride and methylcobalmin. The USP plate count of Dosulepin hydrochloride and methylcobalmin was 7190 and 8590 found to be respectively, which indicates column efficiency for separation. System suitability parameters such as Peak asymmetry, Resolution and Number of theoretical plates are meeting $\mathrm{ICH}$ requirements. The percentage label claim of individual drugs found in formulations were calculated and provided in Table 1. The results of analysis shows that the amounts of drugs estimated were in good agreement with the label claim of the formulations ${ }^{20-21}$.

\section{Method validation}

System suitability studies

System suitability was determined before sample analysis from duplicate injections of the standard solutions of Dosulepin hydrochloride and Methylcobalamin.The column efficiency, resolution and peak asymmetry were calculated for the standard solutions. Resolution between Dosulepin hydrochloride and Methylcobalamin peaks was found to be 7.957. USP tailing (Peak Asymmetry) for Dosulepin hydrochloride and Methylcobalamin were found to be 1.158 and 1.149 respectively. Number of theoretical plates (USP plate count) for Dosulepin hydrochloride and Methylcobalamin were found to be 7190 and 8590 respectively.
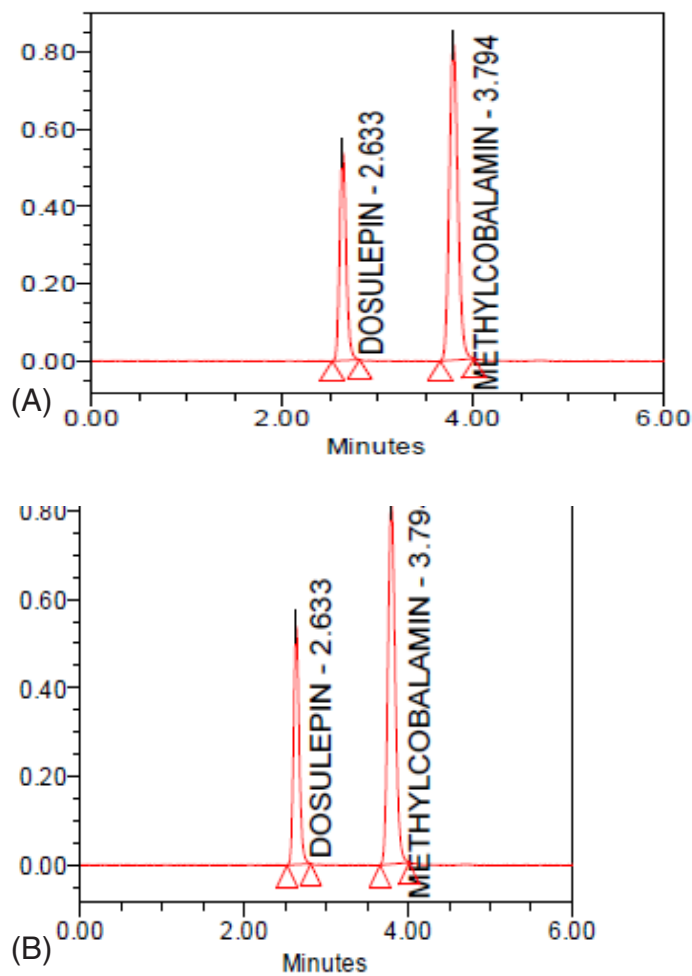

Fig. 2: Typical chromatograms of Dosulepin hydrochloride and Methylcobalamin (A) Standard (B) Formulation

Table 1: Assay results

\begin{tabular}{llll}
\hline sample & $\begin{array}{l}\text { Label } \\
\text { claim } \\
(\mathbf{m g} / \mathrm{tab})\end{array}$ & $\begin{array}{l}\text { Amount } \\
\text { present } \\
(\mathbf{m g} / \mathrm{tab})\end{array}$ & $\begin{array}{l}\text { \%Label } \\
\text { claim } \\
(\% \mathrm{w} / \mathrm{w})\end{array}$ \\
\hline $\begin{array}{l}\text { Dosulepin } \\
\text { hydrochloride }\end{array}$ & 75 & 74.24 & 98.99 \\
Methylcobalamin & 1.5 & 1.45 & 99.77 \\
\hline
\end{tabular}


The values obtained demonstrated the suitability of the system for the analysis of this drug combinations, system suitability parameters may fall within $\pm 3 \%$ standard deviation range during routine performance of the method $^{22,23}$.

\section{Specificity}

Specificity is the ability to assess unequivocally the analyte in presence of components which may be expected to be present. Typically these might include impurities, degradants, matrix, etc. Placebo interference was evaluated by analyzing the placebo prepared by the test method. No peak due to placebo was detected at the retention time of Dosulepin hydrochloride and Methylcobalamin. The specificity of the developed method was also conducted in presence of its degradation products.

\section{Precision}

The precision of method was verified by repeatability and intermediate precision. Repeatability was checked by injecting six individual sample preparations of Dosulepin hydrochloride and Methylcobalamin tablets. Percent relative standard deviation (RSD) of the area for each drug was calculated. The intermediate precision of the method was also evaluated using different analysts and different instruments and performing the analysis on different days. The results of precision study are provided in Table 2.

\section{Accuracy}

The accuracy of the method was determined by recovery experiments. The recovery studies were evaluated in triplicate using three concentration levels $50 \%, 100 \%$ and $150 \%$. The percentage recovery data was obtained, added recoveries of standard drugs were found to be accurate (Table 3 \& 4).

\section{Linearity and Range}

The linearity of the method was determined at five concentration levels $(50 \%, 75 \%, 100 \%$, $125 \%$ and $150 \%)$. Linearity test solutions were prepared by diluting the stock solutions to the required concentrations. The calibration curves were plotted between the responses of peak area versus concentration of analyte. The slope and intercept value for calibration curve was $y=16616$ $x(r 2=0.99)$ for Dosulepin and $y=19288 \times(r 2=0.99)$ for Methylcobalamin. The result (Table 5) shows that an excellent correlation exists between areas and concentration of drugs within the concentration range. Calibration curves are presented in Fig. 3.

\section{Limit of detection \& Limit of quantification (LOD \& LOQ)}

Limit of quantification and detection were predicted by plotting linearity curve for different nominal concentrations of Dosulepin and Methylcobalamin (Table V). Relative standard deviation (ó) method was applied, the LOQ and LOD values were predicted using following formulas. Precision was established at these predicted levels.
(a) $L O Q=10 \sigma / S$
(b) LOD $=3.3 \sigma / \mathrm{S}$

Where

Table 2: Precision studies of Dosulepin and Methyl cobalamin

\begin{tabular}{lccccc}
\hline $\begin{array}{l}\text { S. } \\
\text { No }\end{array}$ & $\begin{array}{c}\text { Sample } \\
\text { Wt }\end{array}$ & $\begin{array}{c}\text { Area of } \\
\text { Dosulepin }\end{array}$ & $\begin{array}{c}\text { Area of } \\
\text { Methylcobalmin }\end{array}$ & $\begin{array}{c}\text { \% Assay of } \\
\text { Dosulepin }\end{array}$ & $\begin{array}{c}\text { \% Assay of } \\
\text { Methylcobalamin }\end{array}$ \\
\hline 1 & 612.20 & 2561486 & 5107686 & 99 & 100 \\
2 & 612.20 & 2566264 & 5109813 & 99 & 100 \\
3 & 612.20 & 2567259 & 5103460 & 99 & 100 \\
4 & 612.20 & 2565597 & 5109276 & 99 & 100 \\
5 & 612.20 & 2560401 & 5109631 & 99 & 100 \\
6 & 612.20 & 2563067 & 5107125 & 99 & \\
Average & 99 & 100 & & & \\
STD & 0.11 & 0.05 & & & \\
\%RSD & 0.11 & 0.05 & & & \\
\hline
\end{tabular}


Table 3: Accuracy of Dosulepin

\begin{tabular}{|c|c|c|c|c|c|c|}
\hline $\begin{array}{l}\text { Spiked } \\
\text { Level }\end{array}$ & $\begin{array}{l}\text { Sample } \\
\text { Weight }\end{array}$ & $\begin{array}{c}\text { Sample } \\
\text { Area }\end{array}$ & $\begin{array}{l}\mu \mathrm{g} / \mathrm{ml} \\
\text { added }\end{array}$ & $\begin{array}{l}\mu \mathrm{g} / \mathrm{ml} \\
\text { found }\end{array}$ & $\begin{array}{c}\% \\
\text { Recovery }\end{array}$ & Mean \\
\hline $50 \%$ & 306.10 & 1289463 & 742.500 & 748.53 & 101 & 100 \\
\hline $50 \%$ & 306.10 & 1280085 & 742.500 & 743.09 & 100 & \\
\hline $50 \%$ & 306.10 & 1283479 & 742.500 & 745.06 & 100 & \\
\hline $100 \%$ & 612.20 & 2564970 & 1485.000 & 1488.96 & 100 & 100 \\
\hline $100 \%$ & 612.20 & 2567326 & 1485.000 & 1490.33 & 100 & \\
\hline $100 \%$ & 612.20 & 2564724 & 1485.000 & 1488.82 & 100 & \\
\hline $150 \%$ & 918.30 & 3847770 & 2227.500 & 2233.63 & 100 & 100 \\
\hline $150 \%$ & 918.30 & 3842991 & 2227.500 & 2230.86 & 100 & \\
\hline $150 \%$ & 918.30 & 3841600 & 2227.500 & 2230.05 & 100 & \\
\hline \multicolumn{7}{|c|}{ Table 4: Accuracy of Methylcobalamin } \\
\hline $\begin{array}{l}\text { Spiked } \\
\text { Level }\end{array}$ & $\begin{array}{l}\text { Sample } \\
\text { Weight }\end{array}$ & $\begin{array}{c}\text { Sample } \\
\text { Area }\end{array}$ & $\begin{array}{l}\mu \mathrm{g} / \mathrm{ml} \\
\text { added }\end{array}$ & $\begin{array}{l}\mu \mathrm{g} / \mathrm{ml} \\
\text { found }\end{array}$ & $\begin{array}{c}\% \\
\text { Recovery }\end{array}$ & Mean \\
\hline $50 \%$ & 306.10 & 2550202 & 15.000 & 14.95 & 100 & 100 \\
\hline $50 \%$ & 306.10 & 2558483 & 15.000 & 15.00 & 100 & \\
\hline $50 \%$ & 306.10 & 2554898 & 15.000 & 14.98 & 100 & \\
\hline $100 \%$ & 612.20 & 5103632 & 30.000 & 29.92 & 100 & 100 \\
\hline $100 \%$ & 612.20 & 5102094 & 30.000 & 29.91 & 100 & \\
\hline $100 \%$ & 612.20 & 5106737 & 30.000 & 29.93 & 100 & \\
\hline $150 \%$ & 918.30 & 7657401 & 45.000 & 44.89 & 100 & 100 \\
\hline $150 \%$ & 918.30 & 7658443 & 45.000 & 44.89 & 100 & \\
\hline $150 \%$ & 918.30 & 7657613 & 45.000 & 44.89 & 100 & \\
\hline
\end{tabular}

Table 5: Linearity of Dosulepin and Methylcobalamin

\begin{tabular}{|c|c|c|c|c|c|c|c|c|c|}
\hline \multirow[b]{2}{*}{$\%$ Conc. } & \multicolumn{4}{|c|}{ Dosulepin } & \multicolumn{5}{|c|}{ Methylcobalamin } \\
\hline & Area & $\mathrm{ug} / \mathrm{ml}$ & LOD & $\overline{L O Q}$ & \% Conc. & Area & $\mathrm{ug} / \mathrm{ml}$ & LOD & LOQ \\
\hline 50 & 1288348 & 750 & $\mathrm{~S} / \mathrm{N}$ & 1634 & 50 & 2556443 & 15 & $\mathrm{~S} / \mathrm{N}$ & 31 \\
\hline 75 & 1920207 & 1125.00 & 2.754 & 9.180 & 75 & 3827829 & 22.5 & 2.9032 & 9.6774 \\
\hline 100 & 2563766 & 1500.00 & & & 100 & 5103999 & 30 & & \\
\hline 125 & 3206208 & 1875 & & & 125 & 6377989 & 37.5 & & \\
\hline 150 & 3844192 & 2250 & & & 150 & 7659637 & 45.00 & & \\
\hline
\end{tabular}

Table 6: Robustness of Dosulepin

\begin{tabular}{lccccc}
\hline Sample Name & Rt & Area & USP Tailing & USP Plate count & S/N \\
\hline TEMP-1 & 2.578 & 3877749 & 1.183 & 6769 & 464.05 \\
TEMP-2 & 2.562 & 3646231 & 1.185 & 7342 & 472.87 \\
FLOW-1 & 3.005 & 5268944 & 1.179 & 7848 & 599.76 \\
FLOW-2 & 2.268 & 3675385 & 1.176 & 6222 & 499.61 \\
\hline
\end{tabular}



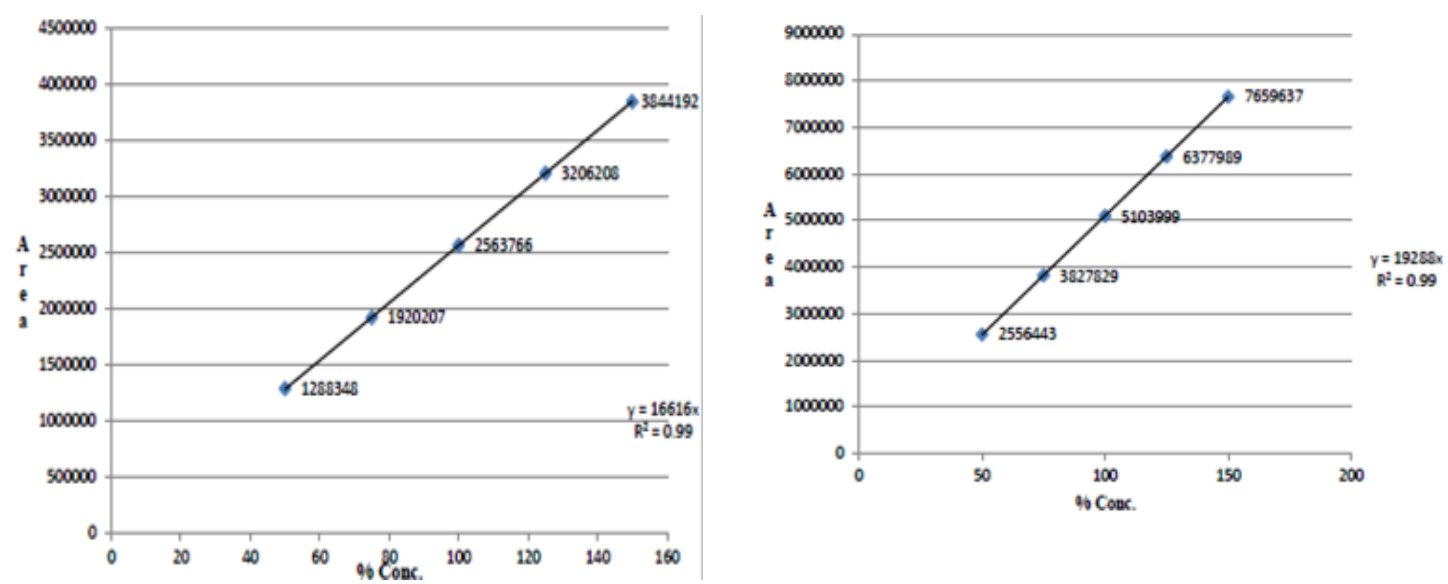

Fig. 3: Linearity graphs of Dosulepin and methyl cobalamin

$\sigma=$ residual standard deviation of response

$\mathrm{S}=$ slope of the calibration curve.

LOQ and LOD values for Dosulepin and methylcobalamin were found to be $9.180,2.754$ and $9.677,2.903$ respectively.

\section{Robustness}

Robustness of the method was determined by making slight changes in the chromatographic conditions and system suitability parameters for Dosulepin hydrochloride Methylcobalamin standard and the resolution, USP Tailing and USP Plate count were recorded. The variables evaluated in the study were column temperature $\left( \pm 5^{\circ} \mathrm{C}\right)$, flow rate $( \pm 0.2 \mathrm{~mL} /$ $\min )$. It was observed that there were no marked changes in the chromatograms, which demonstrates that the method developed is rugged and robust (Table 6 \& 7).

\section{Forced degradation studies}

Based on the results of the stress studies, the degradation behavior of Dosulepin hydrochloride and Methylcobalamin is as follows.

\section{Acid degradation}

Dosulepin and Methylcobalamin were undergoing degradation in $5 \mathrm{~N} \mathrm{HCl}$ at $70^{\circ} \mathrm{C}$ for 10 min moderately. The impurities formed during this study are well separated from main drug peaks and mass balance is found to be in acceptable limit. Peak purity of drugs also matches (Table 8, Figure $6(A)$.

Table 7: Robustness of Dosulepin

\begin{tabular}{lccccc}
\hline Sample Name & Rt & Area & USP Tailing & USP Plate count & S/N \\
\hline TEMP-1 & 3.897 & 7425147 & 1.177 & 7989 & 635.11 \\
TEMP-2 & 3.802 & 6964485 & 1.174 & 8811 & 670.73 \\
FLOW-1 & 4.548 & 10059395 & 1.171 & 8911 & 816.17 \\
FLOW-2 & 3.433 & 7024245 & 1.193 & 7317 & 688.34 \\
\hline
\end{tabular}

\section{Base degradation}

Dosulepin and Methylcobalamin were found to be slightly unstable in $5 \mathrm{~N} \mathrm{NaOH}$ at $70^{\circ} \mathrm{C}$ for $5 \mathrm{~min}$. The major degradation peaks are well separated from drug peaks and well resolved. Mass balance is found to be in acceptable limit. Peak purity of drugs also matches (Table 8, Figure 4 (B).

\section{Oxidation degradation}

Dosulepin and Methylcobalamin were found to be slightly unstable under conditions of $3 \%$ hydrogen peroxide at $70^{\circ} \mathrm{C}$ for $10 \mathrm{~min}$. The major impurities in the study were resolved with drug peaks. Mass balance is found to be in acceptable limit. Peak purity of drugs also matches (Table 8, Fig. 6 (C). 
Table 8: Degradation studies for Dosulepin and Methylcobalamin

\begin{tabular}{|c|c|c|c|c|c|c|c|}
\hline \multirow{2}{*}{$\begin{array}{l}\text { Stress } \\
\text { condition }\end{array}$} & \multirow{2}{*}{$\begin{array}{l}\text { Sample } \\
\text { weight }\end{array}$} & \multicolumn{3}{|c|}{ Dosulepin } & \multicolumn{3}{|c|}{ Methylcobalamin } \\
\hline & & Area & $\%$ Assay & $\%$ Deg. & Area & $\%$ Assay & $\%$ Deg. \\
\hline Acid & 612 & 2434079 & 94 & 5 & 4662402 & 91 & 9 \\
\hline Base & 612 & 2429039 & 94 & 5 & 4843956 & 95 & 5 \\
\hline Peroxide & 612 & 2421056 & 94 & 5 & 4759184 & 93 & 7 \\
\hline Heat & 612 & 2470776 & 96 & 3 & 4979080 & 98 & 2 \\
\hline Light & 612 & 2468072 & 95 & 4 & 4977156 & 98 & 2 \\
\hline
\end{tabular}

\section{Thermal degradation}

Dosulepin and Methylcobalamin were found to be stable to thermal exposure. Partial degradation was take place. Impurities formed well resolved from main drug peaks.

Mass balance is found to be in acceptable limit. Peak purity of drugs also matches (Table 8, Fig. 4 (D).

(A)

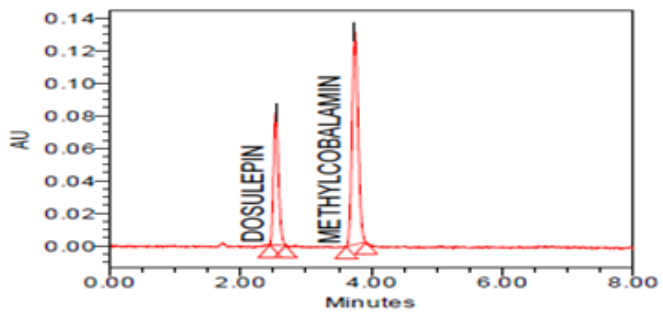

(C)

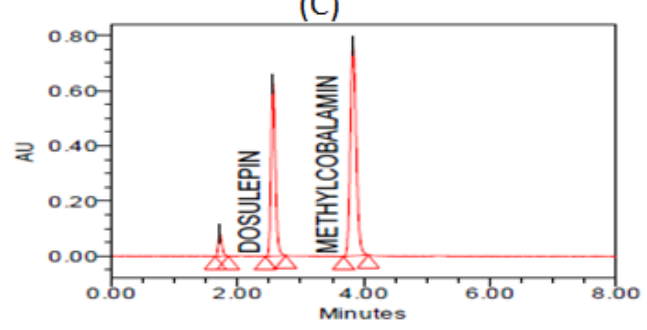

\section{Photolytic degradation}

Upon subjecting the Dosulepin and methylcobalamin sample to both UV and visible light, only partial degradation of was observed.

Testing of a placebo containing preservative leads to formation of number of different impurities with respect to an unstressed placebo. The amount of preservative decreased mainly by

(B)

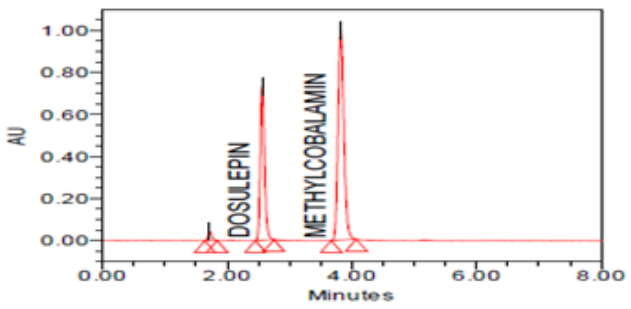

(D)

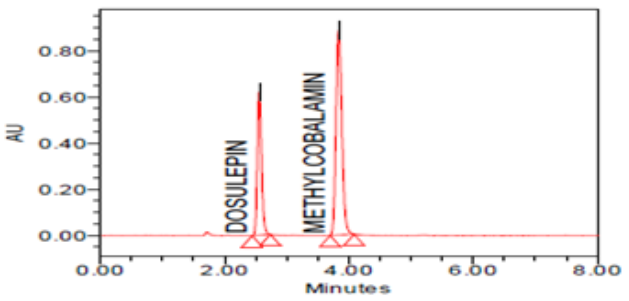

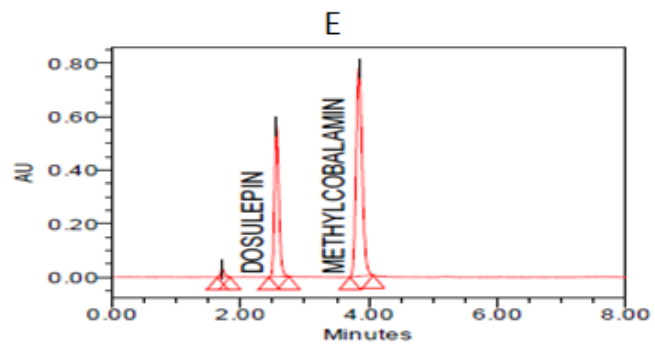

Fig. 4: Typical Chromatograms (A) Acid degradation (B) Alkali degradation (C) Oxidative degradation (D) Thermal degradation (E) Photolytic degradation 
influence of oxidation, light and acid. Mass balance of preservative shows almost $100 \%$. The active ingredients remain almost stable within tested period and mass balance matches (Table 8, Figure $4(E)$.

\section{CONCLUSION}

The proposed HPLC method for the simultaneous estimation of Dosulepin hydrochloride and Methylcobalamin in pharmaceutical dosage forms was found to be simple, sensitive, precise, accurate, linear, robust and rugged during validation. Further this method is stability indicating and can be used for routine analysis of production samples .Hence, this method can easily and conveniently adopt for routine quality control of Dosulepin hydrochloride and Methylcobalamin in pure and its pharmaceutical dosage forms.

\section{ACKNOWLEDGEMENTS}

Authors are thankful to Department of Pharmaceutical Sciences, Jawaharlal Nehru Technological University, Hyderabad and Rainbow Pharma training lab, Kukatpally, for providing instruments and analytical support. Authors are also thankful to Dr.Reddy's Laboratories Ltd. for providing Dosulepin hydrochloride and Methylcobalamin standards as gift samples.

\section{REFERENCES}

1. Sweetman, S. C., (ed), Martindale, The Complete Drug Reference, $37^{\text {th }}$ ed., The pharmaceutical press, London, 2011.

2. Budavari, S, (ed), The Merck Index, $13^{\text {th }}$ ed. NJ: Merck \& Co, Inc; Whitehouse station, 2006.

3. Pawlak, Z., Clark, B.J. J. Pharm. Biomed. Anal. 1989, 7, 1903-1907.

4. Kawahara, K., Awaji, T., Uda, K., Sakai, Y. J. Pharm. Biomed. Anal. 1987, 5, 183-189.

5. Sameer, A., Abdulrahman, M., Basavaiah, K., Cijo, M. X., Vinay, K. B. J. Appl. Spectrosc. 2012: 79, 780-787.

6. Walash, M. I., Belal, F., El-Enany, N., Elmansi, H. Int. J. Biol. Sci. 2010: 6, 327-34.

7. Abdel Ghani, N. T. A., El-Nashar, R.M., Bioumy, A.A. Analyt. Lett. 2004, 37, 32373254.

8. Taha, E. A., Soliman, S.M., Abdellatef, H.E., Ayad, M.M. Mikrochim. Acta. 2002, 140, 175-182.

9. Taha, E.A. Anal. Bioanal. Chem. 2003, 376, 1131-1136.

10. Taylor, P. J., Charles, B.G., Norris, R., Salm, P., Ravenscroft, P.J. J Chrom B Biomed Sci Appl. 1992, 581, 152-155.

11. Saravanan, J., Shajan, A., Joshi, N.H., Varatharajan, R., and Valliappan, K. A. Int. J. Che. and Pharm., 2010: 1, 13-16

12. $\mathrm{ICH}(\mathrm{Q} 2$ (R1); Validation of Analytical Procedures: Text and methodology. International Conference on Harmonization, Geneva, (2005).
13. ICH, Q6A; Specifications: Test Procedures and Acceptance Criteria for New Drug Substances and New Drug Products: Chemical Substances, Geneva, (1999)

14. FDA, Guidance for Industry on Analytical Procedures and methods Validation Chemistry, Manufacturing, and Controls Documentation (draft), Rockville, MD, (2000).

15. ICH, Q1A (R2) Stability Testing of New Drug Substances and Products, International Conference on Harmonization, Geneva, (2003).

16. $\mathrm{ICH}, \mathrm{Q} 1 \mathrm{~B}$ Stability Testing: Photostability Testing of New Drug Substances and Products, International Conference on Harmonization, Geneva, (1996).

17. Maheshwaran, R., FDA Perspectives: Scientific Considerations of Forced Degradation Studies in ANDA Submissions, Pharmaceutical Technology, 2012: 36, 73-80.

18. Snyder, L.R., Introduction to modern liquid chromatography, $3^{\text {rd }}$ Ed., Wiley, Newyork, (2010).

19. Snyder, L.R., Kirkland, J.J., Glajch, J.L., Practical HPLC Method Development, $2^{\text {nd }}$ ed., Wiley, New York, (1997).

20. United States Pharmacopeial convention: United States Pharmacopoeia 36; National Formulary 31, US Pharmacopoea Convention, Rockville, MD, (2013).

21. European Pharmacopeia 7.0, European Directorate of Quality Medicine. 